\title{
Analysis and Research ON CNC Lathe Professional Skill Appraisal Theory Test Base on FANUK 0i
}

\author{
Yongjiu Chen \\ Applied Technology College, Jilin University, Changchun, China
}

Email address:

cyj@jlu.edu.cn

\section{To cite this article:}

Yongjiu Chen. Analysis and Research ON CNC Lathe Professional Skill Appraisal Theory Test Base on FANUK 0i. Science Innovation. Vol. 6, No. 3, 2018, pp. 129-133. doi: 10.11648/j.si.20180603.13

Received: April 26, 2018; Accepted: June 13, 2018; Published: June 22, 2018

\begin{abstract}
The occupational skills appraisal and the vocational qualification certificate have an important position in Higher Vocational Education. The vocational qualification certificate has a profound influence on student employment. Vocational education program based on the "double certificate"system makes far-reaching requirements on vocational qualification certificate. In order to make more students to pass the CNC lathe theoretical examination, increasing the chance of obtaining $\mathrm{CNC}$ lathe professional qualification certificates and improving the employment competitiveness of students majoring in numerical control and mechatronics, the composition and distribution of knowlege point of CNC lathe theory test are analysised in detail based on the FUNAC 0I CNC system in this paper. This paper put forward a few suggestions on how to enhance the training pre the theory examination and how to increase theoretical test scores.
\end{abstract}

Keywords: CNC Lathe, Professional Skill Appraisal, Professional Qualification Certificate, Knowledge Points, Double Certificate

\section{基于FANUK 0i的数控车工职业技能鉴定理论试题分析与研究}

\section{陈永久}

应用技术学院, 吉林大学, 长春, 中国

\section{邮箱:}

cyj@jlu.edu.cn

摘要：针对职业技能鉴定和职业资格证书在高职教育中的重要地位以及职业资格证书对学生就业的深远影响，基于“双 证书”制度的高职培养方案中, 对职业资格证书的获取提出了严格要求。为了使更多的学生能够顺利通过数控车工职业 技能鉴定理论考核, 增加获取数控车工职业资格证书的机会, 提高数控专业及机电一体化技术专业学生的就业竞争力, 基于FUNAC 0i数控系统, 详细分析了的数控车工理论考核试题的组成、类型及知识点的分布规律, 并针对如何加强理 论考核考前辅导, 提高理论考核成绩提出了几点建议。

关键词：数控车工，职业技能鉴定，职业资格证书，知识点，双证书

\section{1. 引言}

教育部等七部委在《关于进一步加强职业教育工作的 若干意见》中明确提出完善就业准入制度和职业资格证书
制度, 积极推进职业院校学生职业资格认证工作; 在《国 家中长期教育改革和发展规划纲要（2010-2020年）》中 提出要积极推进学历证书和职业资格证书“双证书”制度, 推进职业学校专业课程内容和职业标准相衔接。完善就业 
准入制度，执行“先培训，后就业”“先培训，后上岗”的规 定, 进一步明确了职业资格证书教育在职业教育中的作用 [1]; 在2014年《国务院关于加快发展现代职业教育的决定》 中再次重申积极推进学历证书及职业资格证书“双证书” 制度。可见，“双证书”制度在职业教育中的重要地位。为 了保证“双证书”制度的顺利实施, 必须大力推进教育教学 改革, 构建以能力为核心的教学内容与课程体系, 科学设 计知识、能力、素质体系, 对专业课程进行整合, 既保证 专业课程的系统性、连续性, 又涵盖职业技能鉴定大纲中 的内容, 实现学历教育与职业技能鉴定的衔接 [2], 为开展 职业技能鉴定，考取职业资格证书打下坚实的基础。

\section{2. 开展职业技能鉴定的意义及法律依据}

开展职业技能鉴定，推行职业资格证书制度，是落实 党中央、国务院提出的“科教兴国”战略方针的重要举措, 也是我国人力资源开发的一项战略措施。这对于提高劳动 者素质, 促进劳动力市场的建设以及深化国有企业改革, 促进经济发展都具有重要意义[2]。

为了保证推行职业资格证书制度和开展职业技能鉴 定, 《劳动法》第八章第六十九条规定: “国家确定职业 分类，对规定的职业制定职业技能标准，实行职业资格证 书制度, 由经过政府批准的考核鉴定机构负责对劳动者实 施职业技能考核鉴定”。《职业教育法》第一章第八条明 确指出: “实施职业教育应当根据实际需要, 同国家制定 的职业分类和职业等级标准相适应, 实行学历文凭、培训 证书和职业资格证书制度”。这些法规确定了国家推行职 业资格证书制度和开展职业技能鉴定的法律依据。

\section{3. 职业资格证书制度的内涵及对学生就业的影 响}

\section{1. 职业资格证书的内涵}

职业资格证书制度作为一项科学的评价人才、推动劳 动就业的制度, 早在1994年就已经建立。作为国家劳动管 理的重要组成部分, 也是劳动就业制度的一项重要内容, 其本质是一种特殊形式的国家考试制度。它反应了社会生 产力发展的必然要求, 同时也是一个社会文明进步程度的 重要标志[3]。组织学生参加职业技能鉴定, 获取职业资格 证书, 是职业学校培养学生技能的重要途径 [4]。

长期以来, 职业资格证书制度引导和规范着职业教育 的发展方向。职业证书制度所具有的社会分层、职业规划 和信息载体功能, 对职业教育产生了外部支撑和内部指导 作用[5]。因此, 职业院校在进行学历教育的同时, 依然要 紧跟职业资格证书改革的步伐, 加强与职业资格证书制度 的衔接。

\section{2. 职业资格证书对学生就业的影响}

研究显示, 影响大学毕业生就业质量的一级指标共 有 11 个, 其中, 工作培训和职业资格证书构成的工作 因子排在第四位。这表明, 职业资格证书是影响大学毕
业生就业质量的一个重要因素, 职业资格证书成为大学 生学识和技能的证明。如果职业资格证书比较缺乏, 则 会对大学毕业生就业质量造成负面影响[6]。

随着经济结构和产业结构的调整, 社会在重视大学生 学历文凭的同时, 更加重视职业资格证书。职业资格证书 在就业方面发挥了越来越重要的作用, 甚至成为很多企业 招聘人才的必要条件技术。《中国制造2025》提出, 制造 业是国民经济的主体, 是立国之本、兴国之器、强国之基。 没有强大的制造业, 就没有国家和民族的强盛。打造具有 国际竞争力的制造业，是我国提升综合国力、保障国家安 全、建设世界强国的必由之路。尽管我国已经是世界第一 制造大国, 在高铁、核电等一些高端装备制造行业居于领 先地位, 但综合实力与制造强国相比还有很大的差距。要 想缩短这种差距, 发展高档数控机床及机器人, 被及时纳 入国家计划中。随着《中国制造2025》的持续推进, 操作 高端数控机床及机器人的数控加工人才将会越来越短缺。 如果学生在校期间就能够考取数控车工（或铣工）的职业 资格证书, 对学生就业并尽快适应这些岗位会有非常大的 帮助。

\section{4. 数控车工职业技能鉴定考核大纲及鉴定形式}

数控车工职业技能鉴定考核大纲是以国家职业标准 为依据, 以行为领域、鉴定范围和鉴定点的形式加以组 织, 列出本等级下应考核的内容。依据国家标准, 职业 资格证书分为初级、中级、高级、技师及高级技师五个 等级。按照规定, 高职学生可以直接报考中级工。中级 数控车工的考试分为理论知识考核和操作技能考核两部 分, 只有两部分都及格, 才视为通过, 可以申请中级工 的职业资格证书。操作技能考核主要考查学生数控机床 操作、数控编程、机械制造技术等方面的技能, 采取实 际操作数控机床加工指定零件的形式, 对学生在加工过 程中编程与操作的正确性、规范性、安全性以及加工零 件的精度、表面粗糙度等方面进行综合考核; 而理论知 识考试侧重于对数控原理及编程、机械制造技术及相关 方面的理论知识的理解和掌握程度 [7]。就考核范围及知 识点的分布而言, 理论考试范围更广、基础性更强、难 度更大。理论考核的知识点是每门课程的精要所在, 它 反映教学目标、体现学习规律、有操作要求、内容经过 笁选等所在, 具有相对的稳定性、完整性、独立性和变 化性等特点 [8]。全面、完整的掌握每门课程的知识点, 将有助于提高学生的考核成绩。表1和图1列出了近几年 报名人数及通过人数的相关数据。通过对这些数据进行 分析可知, 理论考核比实操考核通过的难度更大。换句 话说, 如果理论考核能够通过, 基本上就可以获得数控 车工职业资格证书, 可见理论考核成绩对获取职业资格 证书的影响非常大。因此, 为了增加学生获取职业资格 证书的机会, 我们对近年来吉林省数控车工职业技能鉴 定理论试题进行了细致的分析与整理, 努力寻找考核知 识点的分布规律, 为考前辅导提供理论依据。 
表 1 数控车工职业资格鉴定报名人数与通过人数对比表。

\begin{tabular}{lllll}
\hline 时间 & 报名人数 & 通过人数 & 理论通过人数 & 实操通过人数 \\
\hline 2010 & 38 & 25 & 25 & 34 \\
2011 & 42 & 38 & 38 & 40 \\
2012 & 49 & 28 & 28 & 44 \\
2013 & 17 & 3 & 3 & 17 \\
2014 & 35 & 29 & 29 & 32 \\
2015 & 47 & 40 & 40 & 44 \\
\hline
\end{tabular}

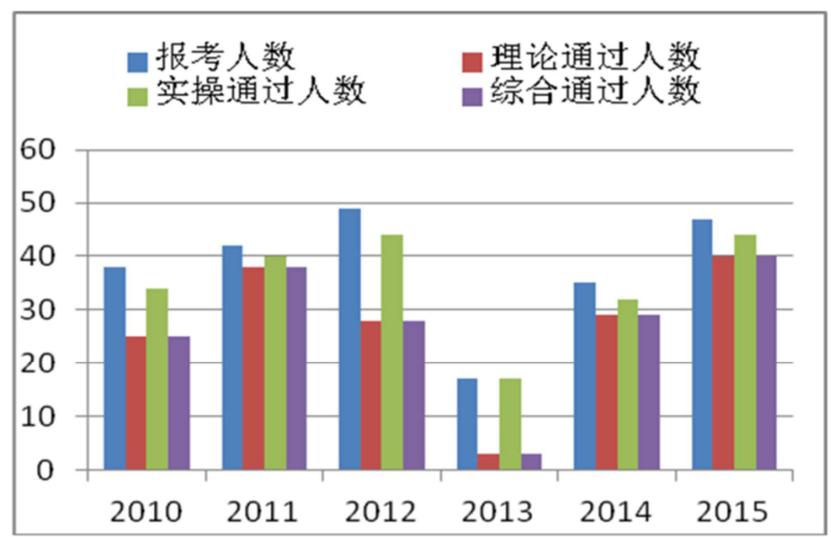

图1 数控车工职业资格鉴定报名人数与通过人数对比图。

\section{5. 理论试题组成及知识点分布规律}

目前, 数控车工中级理论考试采用标准化形式, 总共 为 100 道试题, 其中选择题 80 道, 判断题 20 道。通过对近 年来的数控车工理论试题进行分析, 按照数控车工中级考 核标准及要求, 选择了符合标准化考试形式, 难度适中, 覆盖面广的试卷。通过对这些试卷的内容进行整理, 寻找 知识点的分布规律, 为考前辅导提供一些参考和建议。经 过整理及归类, 试题内容涉及工程制图、计算机辅助设计、 工程材料及热处理、公差配合与技术测量、电工技术、PLC、 单片机、液压及气压传动、金属切削机床、刀具、工艺、 机械零件、数控原理、数控编程及机床操作等。从考核的 知识点来看, 内容分布非常广泛, 几乎涵盖了数控专业及 机电一体化技术专业所有的专业基础课及专业课。为了保 证技能考核顺利进行, 操作者必须熟悉数控系统操作界面 组成、功能、操作过程及方式; 在操作过程中, 操作者必 须严格遵守操作规范, 保证自身的安全。因此, 理论考核 试题中也融入了国家法律法规、着装及安全生产等方面的 内容。按照数控专业及机电一体化技术专业培养方案的要 求，考核内容与相关课程之间的关系如图1所示。

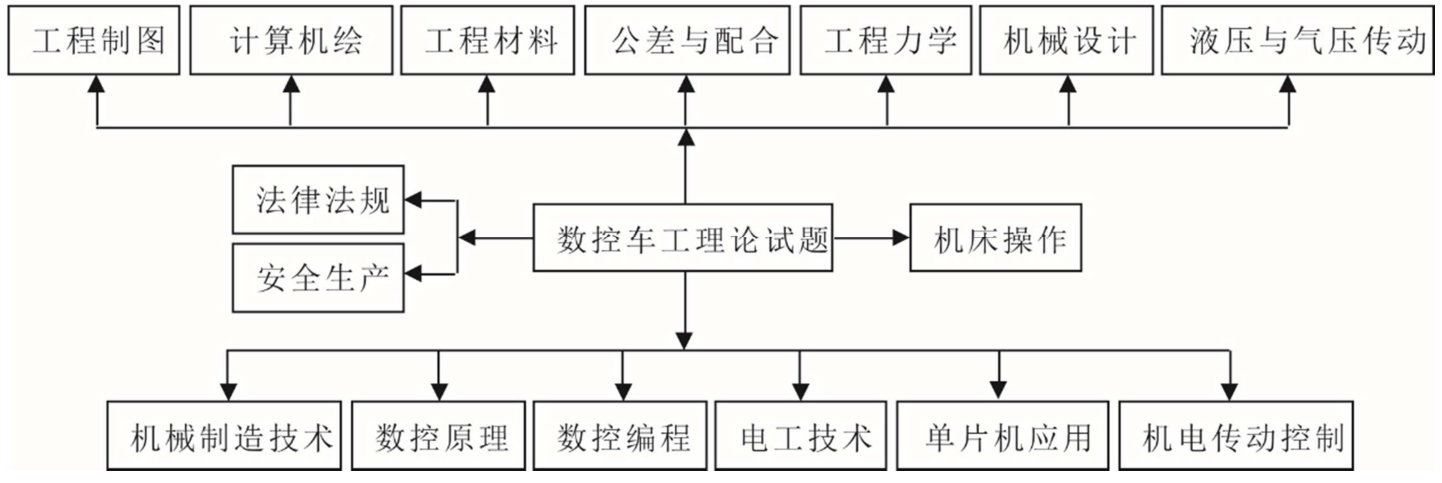

图2 数控车工理论试题与专业课程间的关系。

从知识点的分布来看, 尽管考核内容很多, 知识点涉 及面很广, 但有些知识点出现的频率很低。为了便于数据 分析, 对出现频率较低或不符合数控车工考核大纲要求的 知识点做适当剔除。同时, 将数控车工职业技能鉴定理论 试题中所涉及到的知识点进行分类, 并综合考虑专业培养 方案、课程设置以及职业技能鉴定中关于理论考核的要求 等因素，可以归纳为法律法规及安全生产、工程材料、机 械基础（工程制图及计算机绘图、工程力学、机械设计、 液压与气压传动)、机械制造技术 (公差配合与技术测量、 刀具、工艺、金属切削机床）、电气控制（电工技术、单 片机应用、PLC) 、数控原理及编程、数控车床结构及操 作等七大类。通过对近年来数控车工职业技能鉴定理论考 核试题进行整理和筛选, 选择10套符合考核大纲要求的试
题作为样题。对样题中的知识点进行整理和分类, 并对数 据进行分析, 每套试题中各部分所占比重如表2所示。结 合表中所列数据, 数控车职业技能鉴定理论考试试题, 各 部分所占比重的平均值分别为 $6.8 \% 、 5.5 \% 、 5.9 \% 、 46.2 \%$ 、 $2 \% 、 24 \%$ 及 $9.6 \%$, 取整数后并结合每年理论考试的内容, 各部分所占比例调整为 $7 \% 、 6 \% 、 6 \% 、 46 \% 、 2 \% 、 24 \%$ 及 $10 \%$ 。但是, 由于每年考核的试卷是从题库中随机抽取, 鉴于出题人从事的岗位及所学专业不同, 试题中各部分所 占比重一定会略有不同。不过，考核的内容是依据国家职 业(技能)标准、职业技能鉴定规范(即考试大纲)和相应教 材来确定的, 每套试卷各部分所占比重一般浮动范围在 $10 \%$ 左右属正常, 这样的变动对考前辅导方案的制定及总体的 考核结果不会有实质性的影响。

表2 数控车工职业技能鉴定理论试题知识点分布比。

\begin{tabular}{|c|c|c|c|c|c|c|c|c|}
\hline 序号 & 法律法规及安全生产 & 工程材料 & 机械基础 & 机械制造技术 & 电气控制 & 数控原理及编程 & 数控机床结构及操作 & 合计 \\
\hline 1 & 9 & 4 & 7 & 39 & 2 & 25 & 14 & 100 \\
\hline 2 & 7 & 6 & 4 & 40 & 2 & 26 & 15 & 100 \\
\hline 3 & 6 & 7 & 3 & 77 & 2 & 2 & 3 & 100 \\
\hline 4 & 5 & 2 & 4 & 40 & 0 & 26 & 23 & 100 \\
\hline 5 & 8 & 4 & 3 & 39 & 2 & 31 & 13 & 100 \\
\hline
\end{tabular}




\begin{tabular}{lllllllll}
\hline 序号 & 法律法规及安全生产 & 工程材料 & 机械基础 & 机械制造技术 & 电气控制 & 数控原理及编程 & 数控机床结构及操作 & 合计 \\
\hline 6 & 6 & 8 & 5 & 44 & 3 & 25 & 100 \\
7 & 7 & 5 & 8 & 50 & 2 & 24 & 4 & 100 \\
8 & 8 & 10 & 8 & 46 & 0 & 26 & 2 & 100 \\
9 & 5 & 3 & 10 & 51 & 5 & 25 & 10 & 100 \\
10 & 7 & 6 & 7 & 36 & 2 & 30 & 10 & 13.3 \\
平均值 & 6.8 & 5.2 & 4.3 & 46.3 & 1.8 & 22.2 & 13 & 100 \\
基数 & 8 & 5 & 5 & 40 & 2 & 27 & 100 \\
\hline
\end{tabular}

\section{6. 提高理论考核通过率的几点建议}

按照数控车工职业技能鉴定的考核要求, 理论考核必 须达到 60 分以上才有资格申请职业资格证书。通过以上数 据分析可知, 理论考核的知识点分布非常广泛, 几乎涵盖 了数控专业及机电一体化技术专业所有的专业基础课及 专业课。按照高等职业教育“ $2+1$ ”培养方案的要求, 这些 课程在四个学期都有涉及, 从第一个学期的工程制图到第 四个学期的数控原理及编程技术, 涉及课程多, 时间跨度 长。如果仅仅利用考前两周进行辅导, 即便非常系统的讲 解和训练, 也很难达到考核要求。因此, 必须寻找合适的 辅导方案, 提高理论考核成绩, 才能使更多的学生有机会 申请职业资格证书。

\section{1. 做好考前复习，重点突破}

理论知识考试涉及的科目相对较多, 需要全面的理解 和掌握, 才能取得较好的成绩。因此, 复习时应根据自己 的实际情况, 找出自己的弱项, 有针对性的重点复习和突 破。对理论知识要做到深入了解, 灵活运用, 不能死记硬 背。适当选择一些复习资料提供的模拟练习题, 并在规定 的时间完成。条件允许, 最好在数控车床上进行实际操作 练习, 可以进一步加深对理论知识的理解。

\section{2. 加快教学改革步伐, 将职业资格证书教育纳入高职教 育专业培养方案, 建立考核内容与相关课程之间的联 系}

依照国家职业分类标准及职业资格证书的要求，调整 教学内容和课程体系, 把职业资格证书纳入学生培养方案, 使培养方案包涵相关职业资格证书的知识、素质、能力要 求[1]。将职业技能鉴定考试大纲与专业教学大纲无缝对接, 可有效解决理论考试知识面广、相关课程跨度长的弊端。 在授课过程中, 将技能鉴定考核内容及要求融入相关课程, 加强专业教育相关课程内容与职业标准的相互沟通与衔 接, 使教师在授课过程中有意识的加强这方面的培养和锻 炼, 增强感性认识, 可以有效的提高学生对这些知识点的 关注度。

\section{3. 借助 “互联网+教育” 技术, 建立网络试题库, 使备 考方式灵活多样}

尽管有国家试题库提供模拟试题进行考前复习和强 化训练, 但以往这些考前辅导材料只能使用纸质材料随身 携带, 而纸质材料具有不易保管、易于丢失、不利于反复 的问题, 给备考带来很大的不便。虽然这些考核内容可以 长期保存在计算机中进行复习, 但这些设备随身携带还不
是十分方便。显然，这些备考方式都各有不足。找到理想 的备考方式, 可以有利于提高学生的理论考核成绩, 而利 用“互联网+教育”网络平台就可以有效解决这些问题。按 照数控车工理论考核要求及试卷标准格式, 将经过整理和 分类的试题编成软件, 建立数控车工理论考核网络试题库。 借鉴国家题库的命题思路、依据、范围、考试形式和要求、 试卷结构、题型题量等, 分单元归纳理论知识考核要点, 同时参照国家题库试题类型和难度开发理论试题供学生 练习, 并依据国家题库组卷模式分别组织数控车工职业技 能鉴定理论知识考核模拟试卷[9]。学生通过计算机或手机, 随时随地调阅材料, 反复练习。这样, 可以充分利用了学 生的零散时间以及手机等通讯工具, 改变了原有的单一、 死板的备考形式。这种备考模式不受时间及地域的限制, 可以有效的提高学生对考核内容的熟悉程度。

\section{7. 结论}

总之, 以“既获取学历证书, 又获取职业资格证书”为 特征的“双证书”制度，突出了高等职业教育的实践特色和 人才培养目标要求, 体现了以能力为本位, 以就业为导向 的思想。职业资格证书是学生职业能力的具体体现, 因其 由政府劳动部门颁发, 具有不容置疑的权威性, 受到用人 单位的广泛认可, 成为人才招聘的重要依据[10]。然而, 能否顺利申请, 理论考核是关键之一。近年来的实践证明, 科学合理的知识点分析, 全面的考前辅导是通过理论考核 的关键所在。通过试题分析, 总结知识点的分布规律, 寻 求合适的考前备考方式, 并应用于实践, 使理论考核通过 人数逐年提高, 为数控车工职业资格证书的申请打下坚实 的基础。

\section{参考文献}

[1] 宫清莲.应用型本科院校加强职业资格证书教育的对策研 究 $[J]$.海南广播电视大学学报, 2017, 第2期: 121-124。

[2] 陈志勇.高职院校的职业技能鉴定[J].职业技术教育, 2007.5, 第26期: 64-65。

[3]《职业资格证书与学历证书相互沟通与衔接研究》课题组. 职业资格证书与学历证书相互沟通与衔接研究 [J].武汉职 业技术学院学报, 2002.6, 第2期：8-21。

[4] 刘珍兰.职业资格证书制度的新变化及对职业教育的影响 [J].职教通讯，2017，第17期: 61-63。

[5] 肖鹏程. 郭阳.国家职业资格证书制度对职业教育的功能作 用 [J].职教通讯，2015.1，第13期： 76-80。 
[6] 刘翠花.丁述磊.职业资格证书对大学生就业质量的影响效 应 [J].中国劳动关系学院学报, 2017.6, 第3期: 25-34。

[7] 郭莲芬主编.国家职业技能鉴定指南-数控车工[M].北京: 中 国劳动社会保障部出版社, 2007.9: 1-4。

[8] 杨黎明.终身教育视野下的学历证书与职业资格证书转换 研究 $[\mathrm{J}]$.教育发展研究, 2006, 第10期：52-56。
[9] 杨勇.深化国家题库服务功能助力职业培训与“双证书”制度 $[\mathrm{J}]$.中国成人教育，2015，第10期；159-160。

[10] 万军.基于“双证书”制度高职数控专业实践教学体系的构建 $[J]$.职教通讯，2010.1, 第1期： 85-89。 